tage in respect to the points raised here with the figure of the external anatomy of the adult on plate 73 in my "Sketch of the Life-Histr,ry of the Oyster," already cited.

Mr. Cunningham's inference that the left valve, usually regarded as the lower one, is really the upper, because he finds worm-tubes and hydroids most abundant on the convex or left valve, is founded upon an imperfect acquaintance with the habits of the oyster. For, if living oysters are thrown into the water they will invariably fall upon the bottom with the left valve downward. If dead oyster-shells-free valves-be similarly thrown into the water, they will invariably fall with the hollow side up, and the convex one down. And furthermore, both living and dead shells remain in just the position in which they fall. Dead shells sown as cultch, or collectors, fall in such a position, and most of the spat is "caught" on the exposed parts of the under surface of such shells, whereas little is found on the upper surface. The reason for this is that the sediment which is deposited on the upper surfaces, asphyxiates the young oysterfry and the other larvæ which affix themselves before they can become established and strong enough to resist its effects. The affixed organisms on the exposed inclined under surfaces of the shells, are, on the other hand, protected from the accumulation of sediment.

It is also well known that the right valve of the oyster is always the most deeply pigmented, while the lower or left one is paler. This is always the case when oysters lie almost flat on the bottom. When crowded together on the natural banks in a vertical position, there is less difference between the colours of the valves. This difference is obviously due to some influence exerted by the position of the aspects of the body of the animal in respect to light, the same as in land and aquatic animals generally. I would conclude, for this last reason alone, that the right valve of the oyster is normally always uppermost, were it not for the fact that I have observed all the stages of transition from the spat to the adult condition in confirmation of such a conclusion. It is true that many young oysters have the right valve looking down when allowed to grow upon cultch or shells which have been sown upon the bottom to favour the collection of the spat, but that circumstance by no means subverts the conclusions of such cautious and careful observers as Brooks, Woodward, Jeffrey, Huxley, Horst, and others.

Smithsonian Institution, Washington, U.S.A., JOHN A. RYDER November II

\section{The Rotation Period of Mars}

ONE or two points in Prof. Bakhuysen's investigation of the rotation period of Mars require correction :-

First, my determination of the period, as finally corrected, was $24 \mathrm{~h} .37 \mathrm{~m} .22 \cdot 72 \mathrm{~s}$., correct within 0.02s. The correction arose from the detection of a small clerical error. My final result was deduced from a comparison of observations by myself in 1873 , with observations by Kaiser in 1864, Madler in $1830-$ I837, Sir W. Herschel in the last quarter of the eighteenth century, Huyghens and Hooke in 1666. I have since used the best observations during the oppositions of $188 \mathrm{I}$ and $188_{3}$, without finding any occasion for changing my result even by onehundredth part of a second, though I place no reliance on the second decimal figure.

But, secondly, Prof. Bakhuysen, like Mr. Denning some time since, has taken Kaiser's result uncorrected for the clerical errors-very seriously affecting it -which I detected in 1873 . Kaiser counted three days too many in comparing Hooke's observation with his own: one day through a mistake in correcting for change of style, and two days (apparently) from counting the years $\mathbf{1} 700$ and $\mathbf{1} 800$ as leap-years. His this taking three days too many of terrestrial time had the effectsince three corresponding Martian rotations were taken in-of introducing a deficiency amounting to three times the excess of a Martian over a terrestrial day, that is, $3 \times 37 \mathrm{~m}$. $22.7 \mathrm{~s}$, , or $67,28 \mathrm{I}$ tenths of a second. This, divided by the total number of Martian rotations, about 88,900 , gives as a correction about $0.077 \mathrm{~s}$. to be added to both Kaiser's estimates, making them respectively $24 \mathrm{~h} .37 \mathrm{~m} .22 \cdot 697 \mathrm{~s}$. and $24 \mathrm{~h} .37 \mathrm{~m}$. $22 \cdot 668 \mathrm{~s}$., the mean of which, $24 \mathrm{~h} .37 \mathrm{~m} .22 \cdot 6825 \mathrm{~s}$, is practically the same as the value I assigned, viz. $24 \mathrm{~h} .37 \mathrm{~m} .22 \cdot 7 \mathrm{~s}$

I think it probable that Schmidt (and perhaps Prof. Bakhuysen, too) followed Kaiser so far as the error of three days was concerned. It would naturally be taken for granted that this part of Kaiser's work was free from error. If I had not been determined to find out where and how Kaiser's calculations differed from my own, I should not have found out his mistake, for certainly one would not expect to find two large errors in a work períectly free from small ones. But so it was. I may remark that Prof. Newcomb, of Washington, went through my calculation, finding it correct, and that Kaiser really had made the mistake I indicated.

As this correction re-established what Kaiser had doubted, the accuracy of Hooke's observations, and of my own interpretation of them, Prof. Bakhuysen's correction is scarcely ad. missible, For a difference of o'06s., multiplied by 88,900 for the Martian rotations between Hooke and Kaiser in 1873, gives a total discrepancy of an hour and a half, nearly all of which must be assigned to Hooke's observations and Huyghens' (which I brought into agreement with Hooke's by correcting Kaiser's one-day error for change of style).

$$
\text { 5, Montague Street, Russell Square, W.C., November } 23
$$

\section{Beloit College Observatory}

MY attention has been called to a paragraph in NATURE (vol. xxxii. p. 5I4), which, quoting from Science, speaks of "the Astronomical Observatory of Beloit College as closed for lack of funds." it is not strange that you express surprise at this announcement. Permit me to say that it is positively untrue. So far as I can learn, the only authority for it is a strange and entirely unwarranted statement from our late Director. Mr. Tatlock's connection with our Observatory closed on July I last. Within one week of that date Mr. Charles A. Bacon was appointed his successor, and a few weeks later he appeared and took charge. He has already proved himself competent, both as an observer and as an instructor. New arrangements are made for both meteorological and astronomical observations, and special attention will be given to solar and spectroscopic work. Though not richly endowed, our "Smith Observatory" is well equipped, and under its present direction its facilities will be made helpful to both the advancement and the diffusion of science. A. L. CHA PIN

Beloit College, Wisconsin, October 31

\section{CONFERENCE OF DELEGATES OF CORRE- SPONDING SOCIETIES OF THE BRITISH ASSOCIATION, HELD AT ABERDEEN}

A NEW branch of the British Association glided unobtrusively into existence at Aberdeen, under the new rules passed in the previous year: I mean the Conference of Delegates of Corresponding Societies. The Committee to whom the general arrangements connected with this new branch is intrusted are now issuing a circular to the Corresponding Societies, signed by myself as its Chairman, and by Prof. Meldola as its Secretary, in which they give an account of the proceedings at Aberdeen, with comments thereon. Much of this will be of general interest, as it helps to explain the functions of the Conference, which, as the proceedings showed, were imperfectly understood by many of the delegates themselves. The report is too long to ask you to print it in full, and on the other hand its general purport is more easily seized by leaving out details. I therefore limit myself to sending you extracts from it, with connectinglinks of explanation to make them read continuously.

The Corresponding Societies Committee of the British Association beg to lay the following statement of work done at Aberdeen, with comments thereon, before the Presidents and Councils of the various Societies whose applications for enrolment as Corresponding Societies of the British Association had been granted.

The Conference of Delegates was held on Thursday, September 1o, and on Tuesday, September 15, both meetings having been called at 3.15 p.m., and lasting in each case about one hour. 
(Here follows a list of the various Corresponding Societies and of the attendance of their respective representatives.)

At the first meeting

The Secretary read the first report of the Corresponding Societies Committee, which had been presented to the Council and accepted by the General Committee of the British Association. Methods of procedure were then discussed, and explanations as to the functions of the Conference were given by the Chairman and Secretary in reply to questions or otherwise.

After some informal conversation, invited by the Chairman for an interchange of views, in which suggestions were made as to the nature of the work which might be taken up by Local Societies,

The Chairman explained that al though individual delegates might perhaps like to take advantage of the Conference to mention in formally and when time permitted, any work in which their Society was engaged, with the object of comparing views with, or obtaining assistance from, their brother delegates, it did not fall within the functions of the Conference to suggest or to initiate any scheme of local investigation. It was their function simply to consider how such schemes of the kind, as had been previously considered and adopted by the British Association, through its General Committee, could be best carried out. If any delegate desired to formally propose to the Conference any subject for local investigation, he must do so through the regular channels along which all proposals that receive the sanction of the British Association have to pass. In such cases the subject must first be brought before the Committee of the Section within whose province it lies. It is for that Sectional Committee in the first instance to discuss its merits, and if they approve of the idea they will forward it, backed with their approval, to the Committee of Recommendations, whose duty tt is to revise all such proposals, especially when they involve grants of money, and to submit them in their revised form to the General Committee, under whose sanction they become invested with the full authority of the British Association. Every proposal that has been approved by a Sectional Cominittee, and is concerned with local investigation, will be forwarded under the new rules by the Secretary of the Section to the Secretary of the Conference, at the same time that he forwards it to the Committee of Recommendations. 'The hour and day of the meetings would not admit of delaying the consideration of the proposals by the Conference until they had passed through their final stages and had received the formal sancticn of the Association, but practically little or no difficulty will arise from this forestallment of their final approval, because it is a matter of experience that the deliberate approval of a Sectional Committee is rarely over-ruled on after-consideration, except it be on the grounds of finance, in which case the investigation would simply be abandoned. The real point of importance is that every proposal should pass its first and principal ordeal before a Sectional Committee before it becomes admissible as a subject of formal consideration by the Conference of Delegates. He also reminded the Conference that, in accordance with Rule 7 of the rules reiating to Corresponding Societies, "The Conference may also discuss propositions bearing on the promotion of more systematic observation and plans of operation, and of greater uniformity in the mode of publishing results."

At the second meeting of the Conference the following recommendations for the appointment of Committees intrusted with local inquiries were read to the Conference :-

(1) For the purpose of defining the racial characters of the inhabitants of the British Isles. Dr. Garson explained the objects of this Committee, and invited the co-operation of the Local Societics.

(2) For the purpose of recording the position, height above the sea, lithological characters, size, and origin of the erratic blocks of England, Wales, and Ireland, reporting other matjers of interest connected with the same, and taking measures for their preservation.

(3) For the purpose of investigating the circulation of the underground waters in the permeable formations of England, and the quality and quantity of the water supplied to various towns and districts from these formations.

(4) For the purpose of inquiring into the rate of erosion of the sea-coasts of England and Wales, and the influence of the artificial abstraction of shingle or other material in that action.

Mr. C. E. De Rance made brief statements explanatory of the work of each of the three foregoing Committees, and pointed out the manner in which assistance could be rendered by the Local Societies.

A letter was read from the Secretary of Section D, trans. mitting a recommendation that the subject of the preservation of the native plants of this country should be brought under the notice of the Local Societies, and deputing Prof. W. Hillhouse to bring this subject before the delegates present at the Conference.

In accordance with the foregoing recommendation, Prof. Hillhouse gave numerous instances of the extermination of rare plants from certain localities by dealers, to whom their habitat had become known. He stated that, having been empowered by the Sectional Committee to represent their views on this subject, he had thought it desirable to draw up the following protest :-

"We view with regret and indignation the more or less complete extirpation of many of our rarest or most interesting.native plants. Recognising that this is a subject in which Local Societies of naturalists will take great interest, and can exercise especial influence, we urge upon the delegates of Corresponding Societies the importance of extending to plants a little of that protection which is already accorded by legislature to animals and prehistoric monuments, and of steadily discouraging and, where possible, of preventing any undue removal of such plants from their natural habitats; and we trust that they will bring these views under the notice of their respective Societies."

It was then arranged: (I) That the above gentlemen (or, if more convenient, the Chairman or the Secretary of the Committees they severally represent) should communicate with each of the delegates as soon as the details of their proposed investigations had been matured. (2) That each delegate should thereupon do his best to interest the members of his Society, and, if thought desirable, the Society itself, in the subject of investigation, and should send to his correspondent the names and addresses of such persons in his neighbourhood as might be likely to render willing and effectual help, so as to put him at once in direct communication with them.

It was further agreed that, with the view of making the delegates personally acquainted with one another, it was advisable to give them an opportunity of dining together at an early day during the meeting, and Prof. Meldola was authorised to make the necessary arrangements for the following year at Birmingham. Thursday was suggested as a convenient day for the dinner, but it seems better on reconsideration to adopt Wednesday, at 6. After the dinner the delegates would proceed to the places reserved for them at the opening evening meeting to hear the President's address. Particulars of the place and cost of the dinner, \&c., will be posted on the notice board in the reception room.

The Corresponding Societies Committee have now to point out that, although thirty-nine Societies were admitted as Corresponding Societies, only twenty-three of them nominated delegates. Of the twenty-three delegates only eleven were present at the final meeting to hear the explanations of the gentlemen who attended for the purpose of making them, and of placing themselves in personal communication with the several delegates. The Committee feel sure that the delegates who failed to attend the Conference had not realised the character of the engagement into which they had entered, and that they must have erroneously regarded their title and privileges as purely honorary, and their duties as sinecures. The Corresponding Societies Committee desire it to be clearly understood that such is not the case, as the work intrusted to the delegates is real and important. Conspicuous notices of the times and place of meeting of the Conference had been posted in prominent positions in the reception room and in the sectional rooms, so that ignorance of the meetings could hardly be pleaded in excuse. The position of each delegate is that of a person of scientific influence in his own neighbourhood, who, by the acceptance of his title and its privileges, pledges himself to act as a friendly intermediary between those Committees of the British Association who are occupied with local investigations and the local scientific men who are known to him. It is his duty to make himself well informed of the nature of the proposed inquiries sanctioned by the British Association as personally explained by the represent- 
atives of the respective Committees, and to qualify himself as far as possible for the honourable post of local correspondent. It is in return for the prospect of this very valuable assistance that the position of a member of the General Committee is granted to each delegate, and the privilege is accorded of having published in the Reports of the British Association a catalog 10 of the local investigations of the Society which he represents. Hereafter the Corresponding Societies Committee will take into consideration the advisability of not recommending for reelection those Societies whose delegates fail to attend the meetings of the Conference without adequate explanation.

These views were expressed by the Chairman at the second meeting of the Conference, and they appeared to be fully in harmony with the feelings of the delegates who were present.

The above extracts contain all that is of general importance in the circular letter. Whether or no the Conference of Delegates will grow into an important branch of the British Association remains to be seen. The rules under which it is established ought to secure it from the danger of provoking the jealousy of Local Societies by the assumption of a dictatorial attitude towards them and by interfering in their concerns; on the other hand they as surely prevent it from growing into the anomalous office of an imperium in imperio as regards the British Association. Consequently the success of the Conference appears wholly to depend on an abundant and continuous supply of good work being found for it to do, and on a sufficiency of zeal among the delegates to perform their duties efficiently.

FRANCIS GaLTON

DR. CARPENTER, C.B., F.R.S.

A SHORT sketch of the life and work of the eminent A naturalist who has recently passed from among us will be welcome to the readers of NATURE.

William Benjamin Carpenter was born at Exeter in 1813, and was the fourth child and eldest son of Dr. Lant Carpenter, a Unitarian minister. His sister, Mary Carpenter, who died a few years since, achieved the most important work as a philanthropist, in relation to the treatment of prisoners and to questions affecting our Indian fellow-subjects, and will be remembered by future generations with no less gratitude than her brother.

In his childhood Dr. Carpenter received an excellent education, comprising both classics and the principles of physical science, at the school established by his father at Bristol, and it was hisintention to adopt the profession of a civil engineer. $\mathrm{He}$ was, however, persuaded to accept the opportunity offered by a medical practitioner, Mr. Estlin, of Bristol, and to enter on the study of medicine as apprentice to that gentleman. Shortly after this he was sent, as companion to one of Mr. Estlin's patients, to the West Indies, and on his return from this visit he entered, at the age of twenty, the medical classes of University College, London. After passing the examinations of the College of Surgeons and the Apothecaries' Society he proceeded to Edinburgh, where he graduated as M.D. in 1839 .

His graduation thesis on "The Physiological Inferences to be deduced from the Structure of the Nervous System of Invertebrated Animals" excited considerable attention, especially on account of the views which he advanced as to the reflex function of the ganglia of the ventral cord of Arthropoda.

From the first Dr. Carpenter's work showed the tendency of his mind to seek for large generalisations and the development of philosophical principles. He was a natural philosopher in the widest sense of the term-one who was equally familiar with the fundamental doctrines of physics and with the phenomena of the concrete sciences of astronomy, geology, and biology. It was his aim, by the use of the widest range of knowledge of the facts of Nature, to arrive at a general conception of these phenomena as the outcome of uniform and all-pervading laws. His interest in the study of living things was not therefore primarily that of the artist and poet so much as that of the philosopher, and it is remarkable that this interest should have carried him, as it did, into minute and elaborate investigations of form and structure. Although some of his scientific memoirs are among the most beautifully illustrated works which have been published by any naturalist, yet it is noteworthy that he himself was not a draughtsman, but invariably employed highly skilled artists to prepare his illustrations for him. Yet we cannot doubt that the man who, with his dominant mental tendency to far-reaching speculations, yet gave to the world the minute and ingenious analysis of the beautiful structure of the shells of Foraminifera, had an artist's love of form, and that the part of his life's work (for it was only a part among the abundant results of his extraordinary energy) which was devoted to the sea and the investigation of some of its fascinating living contents, was thus directed by a true love of Nature in which ulterior philosophy had no share.

Two books, Dr. Carpenter has told us, exerted great influence over his mind in his student days: they were Sir John Herschel's "Discourse on the Study of Natural Philosophy" and Lyell's "Principles of Geology"--that great book to which we owe the even greater books of Charles Darwin. Taking the "Principles" in some way as his model, Dr. Carpenter produced in 1839 his first systematic work, under the title "Principles of General and Comparative Physiology, intended as an Introduction to the Study of Human Physiology and as a Guide to the Philosophical Pursuit of Natural History." Admirable as was the execution of this work in many ways, its great merit lay in the conception of its scope. It was in fact the first attempt to recognise and lay down the lines of a science of "Biology" in an educational form. Carpenter's "Comparative Physiology" is the general or elementary "Biology" of the present day-traced necessarily upon the less secure foundations which the era of its production permitted, viz. one year only subsequent to the date of Schwann's immortal " Microscopical Researches."

For five years Dr. Carpenter remained in Bristol, commencing medical practice and marrying in 1840 ; but in I 844 , feeling a distaste for the profession of medicine, he removed to London in order to devote himself entirely to a literary and scientific career. He was encouraged to take this step by the success which his "Comparative Physiology" obtained, a second edition having been called for within two years of the publication of the first. He was appointed Fullerian Professor of Physiology in the Royal Institution during his first year in London, and Professor and Lecturer at University College and at the London Hospital, whilst he was also elected a Fellow of the Royal Society.

In I85 I Dr. Carfenter became Principal of University Hall, the residential institution attached to University College, where he remained until 1859 . During this period he remodelled his treatise on Physiology, issuing the more general biological portion as "Comparative Physiology," whilst that portion dealing with the special physiology of man and the higher animals appeared as his well-known "Human Physiology," which subsequently ran through many editions. The "Human Physiology" is remarkable in the first place for the chapters on the physiology of the nervous system, and especially for the theories enunciated with regard to the relations of mind and brain, and the attempt to assign particular activities to particular portions of the cerebral structure. In arriving at his conclusions Dr. Carpenter had to depend on arguments drawn from the facts of comparative anatomy and of diseased or abnormal conditions in man. There is no doubt at the present day of the acuteness which he displayed in his treatment of the subject, and of the truth in a general way of the results which he formulated. Experiment and a wider range of observation have to some extent corrected-but on the 